\title{
INCIDENCE OF RESIDUAL NEUROMUSCULAR BLOCKADE AT TRACHEAL EXTUBATION: COMPARISON OF ATRACURIUM WITH VECURONIUM
}

\author{
Shwetha S. Naik1, Geetha C. Rajappaㄹ, Rathna N. Rao ${ }^{3}$, Yatish $B^{4}$ \\ 1 Junior Consultant, Department of Neurocritical Care, BGS Global Hospital, Bangalore. \\ ${ }^{2}$ Associate Professor, Department of Anaesthesiology, MS Ramaiah Medical College, Bangalore. \\ 3 Professor and Director, Department of Anaesthesiology and Critical Care, MS Ramaiah Medical College, Bangalore. \\ ${ }^{4}$ Associate Professor, Department of Anaesthesiology, MS Ramaiah Medical College, Bangalore.
}

\begin{abstract}
BACKGROUND: Occurrence of undetected residual neuromuscular blockade is a common event in the post anaesthesia care unit.

AIM: To compare the incidence and degree of residual neuromuscular blockade with the use of intermediate acting neuromuscular blocking agents Atracurium and Vecuronium.

METHODS: 360 patients satisfying the inclusion and exclusion criteria were enrolled in the study and randomly allocated into one of the two study groups of 180 each to receive either Atracurium or Vecuronium intraoperatively. The anaesthesiologist blinded from the study extubated the patient based on the standard clinical criteria and the corresponding Train of Four(TOF) ratios were noted by a blinded research assistant using a TOF watch (TOF- Watch® SX Organon, Ireland Ltd., Dublin, Ireland). Residual neuromuscular blockade was defined as a TOF ratio of $<0.9$. TOF measurements thirty minutes after tracheal extubation were noted in the recovery room.
\end{abstract}

RESULTS: 196 out of the 360 patients had TOF ratio <0.9 with an overall incidence of post-operative residual curarization (PORC) of 54.4\%. Patients in Vecuronium group had a higher incidence of PORC compared to the Atracurium group ( $p=0.003$ ); $9 / 196$ had TOF ratios $0.7-0.79$ and all of them received Vecuronium; 187/196 had TOF 0.8-0.89; $103 / 187$ patients with TOF 0.8-0.89 received Vecuronium, while the rest 84 received Atracurium. All the 360 study subjects had TOF ratio $>0.9$ thirty minutes after tracheal extubation.

CONCLUSION: We conclude from our study that significant post-operative residual curarization (TOF < 0.9 ) exists in majority of patients at the time of tracheal extubation (54.4\% incidence) despite the use of intermediate acting neuromuscular blocking drugs. The incidence and degree of post-operative residual curarization is significantly greater with Vecuronium compared to Atracurium. Thus we suggest that quantitative neuromuscular monitoring is required to assure complete neuromuscular recovery.

KEYWORDS: Atracurium; Vecuronium; Train of four; Post-operative Residual Curarisation.

HOW TO CITE THIS ARTICLE: Shwetha S. Naik, Geetha C. Rajappa, Rathna N. Rao, Yatish B. "Incidence of Residual Neuromuscular Blockade at Tracheal Extubation: Comparison of Atracurium with Vecuronium." Journal of Evolution of Medical and Dental Sciences 2015; Vol. 4, Issue 94, November 23; Page: 15947-15951, DOI: 10.14260/jemds/2015/2323.

INTRODUCTION: Occurrence of undetected residual neuromuscular blockade is common in the Post Anaesthesia Care Unit (PACU). Post-operative Residual Curarization (PORC) was frequent in patients given long acting neuromuscular blocking agents. ${ }^{1}$ Later studies have reported PORC even with intermediate acting neuromuscular blocking agents. $^{2,5}$ In fact, train of four (TOF) ratios $<0.7-0.8$ in the PACU have been detected in $16-42 \%$ of the patients given intermediate acting muscle relaxants for neuromuscular blockade intraoperatively. 2,5,6

Awake volunteers and surgical patients have shown that TOF ratios of 0.7-0.9 can adversely affect respiratory and pharyngeal muscle functions. There have been reports of impairment of protective airway reflexes, upper airway obstruction, a decreased hypoxic ventilatory response, and post-operative hypoxemia.7,10

Financial or Other, Competing Interest: None.

Submission 13-11-2015, Peer Review 14-11-2015,

Acceptance 16-11-2015, Published 21-11-2015.

Corresponding Author:

Geetha C. Rajappa,

Associate Professor, Department of Anaesthesiology,

MS Ramaiah Medical College, Bangalore.

E-mail: jageedha@yahoo.com

DOI:10.14260/jemds/2015/2323.
These reports suggest that anaesthesia care providers are unable to reliably detect residual neuromuscular block in the OR using standard clinical criteria. Studies have recommended that full recovery of neuromuscular block $(\mathrm{TOF} \geq 0.9$ ) should be present at the time of tracheal extubation to avoid undetected PORC.5,8,11 Hence, the present study to detect the extent of residual neuromuscular paralysis by TOF ratio with intermediate acting muscle relaxants at time of tracheal extubation.

The primary objectives of the study are to assess and compare the incidence and degree of post-operative residual neuromuscular blockade in patients at the time of tracheal extubation with the use of intermediate acting Neuromuscular Blocking Drugs (NMBD)-Atracurium and Vecuronium.

METHOD: After obtaining ethical committee clearance, a prospective randomized control study was conducted on three hundred sixty patients. Patients undergoing elective general surgical and gynecological procedures and satisfying the inclusion and exclusion criteria were enrolled into the study. Inclusion criteria were ASA physical status 1 and 2; age group 18-60; surgical procedures under general anesthesia 
with the use of muscle relaxants. Exclusion criteria were: Presence of neuromuscular disorders; patients with hepatic and renal diseases; body mass $>30 \%$ of the ideal body weight; anticipated difficult ventilation or endotracheal intubation; patients receiving drugs known to interfere with neuromuscular transmission.

After obtaining a written informed consent from the study subjects, they were randomly assigned using a computer generated table into one of the two muscle relaxant groups of one hundred eighty patients each:

Group A - patients receiving Atracurium.

Group B - patients receiving Vecuronium.

All patients were premedicated with intravenous Midazolam $1 \mathrm{mg}$. The study subjects were pre-oxygenated for three minutes. Intravenous Fentanyl $2 \mu \mathrm{g} / \mathrm{kg}$ was administered for analgesia and all the patients received Propofol $2 \mathrm{mg} / \mathrm{kg}$ for induction. Muscle relaxation for tracheal intubation was achieved with either Atracurium in the dose of $0.5 \mathrm{mg} / \mathrm{kg}$ for patients categorized under group A or Vecuronium $0.1 \mathrm{mg} / \mathrm{kg}$ for patients categorized under group B. Anaesthesia was maintained with Isoflurane $0.6-1 \%$ in oxygen/nitrous oxide mixture.

Ventilation was controlled to maintain an end tidal carbondioxide between $28-32 \mathrm{mmHg}$. Standard monitoring of electrocardiography (ECG), heart rate (HR), pulsoximetry (sp02), non-invasive blood pressure (NIBP), end tidal carbondioxide (etCO2), core body temperature using a nasopharyngeal probe and neuromuscular monitoring using a TOF watch (TOF-Watch ${ }^{\circledR}$ SX Organon, Ireland Ltd., Dublin, Ireland) was done during the intraoperative period. An upper extremity forced air warming device was placed on all the study patients to maintain core body temperatures $>35^{\circ} \mathrm{C}$ and arm temperature $>32^{\circ} \mathrm{C}$.

TOF monitoring was done using TOF Watch SX by acceleromyography wherein an acceleration transducer was taped to the distal interphalangeal joint of the thumb, and the study arm immobilized with a splint. The study arm was positioned to allow free movement of the thumb; no preload was attached to the thumb. Supramaximal (50mA) squarewave TOF stimulation was delivered to the ulnar nerve via surface electrodes.

Fentanyl in the dose of $0.5 \mu \mathrm{g} / \mathrm{kg}$ was given IV every hour for analgesia during surgical procedure. Repeat doses of muscle relaxants during surgery were administered when two responses of TOF stimulation were visible at the adductor pollicis muscle. Patients in group A received $5 \mathrm{mg}$ of Atracurium while patients in group $B$ received $1 \mathrm{mg}$ of Vecuronium as maintenance doses during surgery. No muscle relaxants were administered during the last 10 minutes of surgical procedure.

Isoflurane was discontinued at the time of last skin suture and patients ventilated with $100 \%$ oxygen. Neuromuscular blockade was reversed with Neostigmine $50 \mu \mathrm{g} / \mathrm{kg}$ and Glycopyrrolate $10 \mu \mathrm{g} / \mathrm{kg}$. Reversal was not attempted until at least two responses to TOF stimulation were visible.

Anesthesiologists blinded from the study were instructed to assess patients for adequacy of neuromuscular reversal using standard clinical criteria recommended in our department:
1. Sustained head lift for 5 seconds.

2. Acceptable spontaneous ventilation (Generating tidal volume $>5 \mathrm{ml} / \mathrm{kg}$ ) and maintaining adequate oxygenation.

3. Ability to respond to verbal commands.

When the anesthesiologist blinded from the study determined that full recovery of neuromuscular function was present using the above mentioned clinical criteria and that tracheal extubation could be performed, TOF ratios were measured by a research assistant blinded to intraoperative anesthetic management using an acceleromyography device (TOF-Watch ${ }^{\circledR}$ SX, Organon). The blinded anaesthesiologist extubating the patient was instructed by the blinded research assistant to delay tracheal extubation if significant muscle weakness was present (TOF ratio $<0.6-0.7$ ).

At the time of tracheal extubation, TOF ratios were measured using acceleromyography (TOF-Watch ${ }^{\circledR}$ SX; Organon). Two consecutive TOF measurements (Separated by 15s) were obtained, and the average of the 2 values was recorded. If measurements differed by $>10 \%$, additional TOF measurements were obtained (up to 4 TOF values), and the closest 2 ratios were averaged. The time intervals between Neostigmine administration, tracheal extubation, and TOF measurements were recorded.

All TOF measurements were obtained by a research assistant not involved in clinical care. Thirty minutes after shifting the patients to the PACU, a second set of TOF ratios was measured as described above. TOF ratio $<0.9$ was used to define residual neuromuscular blockade. The study subjects with TOF ratio $<0.9$ were further assessed for the degree of residual neuromuscular blockade as those with TOF ratios between 0.7-0.79 and TOF between 0.8-0.89. Patients in both the groups were compared with respect to the incidence and the degree of residual neuromusculalar blockade and statistical analysed for significance. Patients with $\mathrm{TOF}<0.9$ were monitored intensely for any adverse respiratory event.

STATISTICAL ANALYSIS: Data are reported as the number of patients, mean \pm SD (Standard deviation). An independent sample t-test was performed on patient demographic and intraoperative variables and Levene's test for equality of variances was used to compare the intragroup differences.

Chi square test was used to compare the incidence and severity of residual neuromuscular blockade between the two groups. The criterion for statistical significance was $P$ value of less than 0.05 .

RESULTS: The groups were comparable with respect to patient demographic variables such as age, gender, height and weight of the patients with no statistical difference. (Table 1).

Statistically significant differences were noted with respect to the total number of redoses of the muscle relaxants and the core body temperature at the time of tracheal extubation among the two groups. Atracurium group had a mean redoses of $2.44 \pm 1.38$ while the Vecuronium group had a mean redoses of $1.53 \pm 1.23$ with $p$ value of 0.001 , which is statistically significant (Table 1 ). The mean core body temperature at the time of tracheal extubation was 
$36.13 \pm 0.27$ for patients in group $A$ and $36.07 \pm 0.26$ for patients in group B with a ' $p$ ' value of 0.036 . Other intraoperative variables such as the mean duration between administration of reversal agents and extubation and the mean duration of surgery did not show any statistically significant difference.

A total of $196(54.4 \%)$ subjects had TOF ratio<0.9, of which $112(57.14 \%)$ patients belonged to the Vecuronium group while the rest $84(42.86 \%)$ patients belonged to the Atracurium group (Table 2). Patients who received Vecuronium had a higher incidence of post-operative residual curarization, which was statistically significant $(\mathrm{p}=0.003)$.

Among the 196patients with TOF ratio $<0.9$, no patient had TOF $<0.7 ; 0.9$ patients had TOF ratios between 0.7-0.79 (All Vecuronium group) and 187patients had TOF ratios between $0.8-0.89$ of $103(55.1 \%)$ received Vecuronium intraoperatively while the rest $84(44.9 \%)$ received Atracurium. This was statistically significant with $\mathrm{P}$ value of 0.0001 suggesting an increased severity of post-operative residual curarization among patients receiving Vecuronium. All the 360 study subjects had TOF ratio $>0.9$ thirty minutes after tracheal extubation. None of the patients had any serious respiratory event requiring intervention.

DISCUSSION: Undetected residual neuromuscular blockade or PORC is commonly seen in the PACU. Residual neuromuscular block can be defined as the presence of signs or symptoms of muscle weakness in the postoperative period with the use of intraoperative NMBD. Patients with adequate neuromuscular recovery should be able to breathe normally, maintain a patent upper airway, and preserve protective airway reflexes, swallow, cough and talk. Most patients (And volunteers) achieve these clinical end points at a TOF ratio of 0.9 .7

In the present study, we have defined residual neuromuscular blockade as a TOF ratio of $<0.9$ using acceleromyography. We detected residual neuromuscular blockade in $54.4 \%$ of our patients. Baillard et al. observed of TOF ratios of $<0.7$ in $42 \%$ of patients who received Vecuronium, but no anticholinesterase. ${ }^{2}$ Norton et al. in their analysis, reported the occurrence of residual neuromuscular blockade in $30 \%$ of their subjects. ${ }^{12}$ A meta-analysis reviewed twenty-four studies (Between 1979 and 2005) for the incidence of postoperative residual curarization. Antagonism of NMBDs was used in $62.1 \%$ of patients, and neuromuscular function was monitored (Qualitatively and quantitatively) in $24.4 \%$ of subjects. When studies using intermediate-acting NMBDs were analyzed, the incidence of TOF $<0.7$ was $12 \%$ and $\mathrm{TOF}<0.9$ was $41 \% .{ }^{13}$ but in contrast another study reported a incidence (13.1\%) of residual neuromuscular blockade in PACU. This was probably because of administration of single dose muscle relaxant at the time of intubation (no repeat dose) with the duration of anaesthesia ranging from 60 to 100 mins. ${ }^{14}$

In our study, among the 196patients with a TOF ratio $<0.9$, 112patients (57.14\%) belonged to the Vecuronium group, while 84 patients $(42.86 \%)$ belonged to the Atracurium group. TOF ratios between $0.8-0.89$ was seen in 187 patients of which 103(55.1\%) patients received Vecuronium while 84(44.1\%) patients received Atracurium.
Thus the incidence and severity of PORC was higher among patients who received Vecuronium for muscle relaxation during surgery in our study.

One study reported that the incidence of postoperative residual neuromuscular block was $64 \%, 52 \%$ and 39\% with use of Vecuronium, Atracurium and Rocuronium respectively. ${ }^{3}$ Debaene et al., observed TOF ratios $<0.7$ and $<0.9$ postoperatively in $16 \%$ and $45 \%$ of patients respectively in the PACU, in patients receiving a single intubating dose of indermediate acting muscle but no reversal agent at end of the procedure. ${ }^{5}$ Even with the use of intermediate-acting NMBDs and its antagonists at the end of the procedure, PORC is still a clinical problem in the PACU. Thus, indicating the need for objective neuromuscular monitoring to be performed per operatively to ensure patient safety. ${ }^{15}$

It has been demonstrated that respiratory and pharyngeal function do not normalize until TOF ratios of 0.8 1.0 are obtained. Pharyngeal function and airway protection were impaired at TOF ratios of 0.9 in awake volunteers. ${ }^{7}$ Eikermann et al. also observed that inspiratory flow impairment and upper airway obstruction occurred frequently at a TOF ratio of $0.83 .{ }^{8}$ About $30 \%$ in awake volunteers with TOF ratios of 0.7 had reduced hypoxic ventilator response. ${ }^{9}$ A correlation between mild residual neuromuscular block and postoperative hypoxemia has been described.10 These findings suggest that removal of an endotracheal tube in the presence of minimal levels of residual block can potentially contribute to adverse pulmonary outcomes. Although, the residual block is relatively short lasting, it may occasionally be prolonged requiring close observation and monitoring of such patients in the recovery ward.

Data suggests that TOF ratios must recover to values $>0.9$ to ensure utmost patient safety. Data derived from volunteer studies have revealed pharyngeal dysfunction with an increased risk for aspiration occur at TOF ratios $<0.9 .7,16$ Impaired inspiratory flow and partial upper airway obstruction have been observed frequently at TOF ratios of 0.8. ${ }^{8}$ Furthermore, minute levels of neuromuscular blockade may cause distressing symptoms in awake patients, which may occur even at TOF ratios $>0.9 .17$ These data suggest that the new "Gold standard" for the minimal acceptable level for neuromuscular recovery is TOF ratio of 0.9 . Neuromuscular transmission monitoring aids in accurate titration, a more rational use of the NMB agents and thus a decreasing the incidence of residual neuromuscular block. ${ }^{18}$

Butterly et al., in their study concluded that PORC is associated with a delayed PACU discharge and the extent of the effect is clinically significant. PACU length of stay was significantly longer in patients with $\mathrm{T} 4 / \mathrm{T} 1<0.9(323 \mathrm{~min})$, compared with patients with adequate recovery of neuromuscular transmission (243min). The incidence of $\mathrm{T} 4 / \mathrm{T} 1<0.9$ was higher in patients receiving Vecuronium. In our study, at thirty minutes after arrival in PACU, all the patients achieved TOF ratio of $>0.9 .19$

The mean core body temperature of patients who received Atracurium was $36.13 \pm 0.27$ degree centigrade while those who received Vecuronium was $36.07 \pm 0.26$ degree centigrade with a ' $p$ ' value of 0.036 which is statistically 
significant. But the difference in core body temperature was $0.06^{\circ} \mathrm{C}$ and was clinically insignificant.

Tom Heier et al., in their review article stated that hypothermia reduce muscle strength irrespective of the presence of neuromuscular blocking drugs. ${ }^{20}$ The duration of neuromuscular blockade may increase two-fold with a $2^{\circ} \mathrm{C}$ reduction in body temperature.

There is a parallel decline in central body and muscle temperatures, provided there is no asperipheral vasoconstriction. At a body temperature less than $36^{\circ} \mathrm{C}$ (Corresponding to a muscle temperature of approximately $35^{\circ} \mathrm{C}$ ) reduction in muscle strength must be anticipated. The efficacy of Neostigmine is not altered during mild hypothermia. The use of a nerve stimulator is strongly recommended to monitor the effect of neuromuscular blocking drugs during intraoperative hypothermia.

In conclusion, we determined that significant residual paralysis was present in the majority of patients at the anticipated time of tracheal extubation using standard clinical criteria. Despite the use of strict protocol to evaluate adequate reversal of an intermediate-acting muscle relaxant with careful clinical examination, clinicians were consistently unable to achieve acceptable levels of neuromuscular recovery in the operating room. In order for the anesthesiologists to be assured that neuromuscular recovery is complete and that respiratory and pharyngeal muscle function has returned to normal, quantitative neuromuscular monitoring is required especially if vecuronium is employed as muscle relaxant.

\section{REFERENCES:}

1. Viby-Mogensen J, Jorgensen BC, Ording H. Residual curarization in the recovery room. Anesthesiology 1979; 50: 539-41.

2. Baillard C, Gehan G, Reboul-Marty J, Larmignat P, Samama CM, Cupa M. Residual curarization in the recovery room after Vecuronium. Br J of Anaesth 2000; 84: 394-5.

3. A H. Hayes, R. K. Mirakhur, D. S. Breslin, J. E. Reid, K. C. McCourt. Postoperative residual block after intermediate-acting neuromuscular blocking drugs. Anaesthesia 2001; 56: 312-18.

4. Gatke MR, Viby-Mogenson J, Rosenstock C, Jensen FS, Skovgaard LT. Post-operative muscle paralysis after Rocuronium: less residual block when acceleromyography is used. Acta Anaesthesiol Scand 2002; 46: 207-13.

5. Debaene B, Plaud B, Dilly MP, Donati F. Residual paralysis in the PACU after a single intubating dose of non-depolarizing muscle relaxant with an intermediate duration of action.

Anesthesiology 2003; 98: 1042-8.

6. Kim KS, Lew SH, Cho HY, Cheong MA. Residual paralysis induced by either Vecuronium or Rocuronium after reversal with pyridostigmine. Anesth Analg 2002; 95:1656-60.
7. Sundman E, Witt H, Olsson R, Ekberg O, Kuylenstierna R, Eriksson LI. The incidence and mechanisms of pharyngeal and upper esophageal dysfunction in partially paralyzed humans: Pharyngeal videoradiography and simultaneous manometry after Atracurium. Anesthesiology 2000; 92:977- 84.

8. Eikermann $\mathrm{M}$, Groeben $\mathrm{H}$, Husing J, Peters J. Accelerometry of adductor pollicis muscle predicts recovery of respiratory function from neuromuscular blockade. Anesthesiology 2003;98: 1333-7.

9. Eriksson LI, Sato M, Severinghaus JW. Effect of a Vecuronium induced partial neuromuscular block on hypoxic ventilatory response. Anesthesiology 1993;78:693-9.

10. Bessinger U, Schimek F, Lenz G. Postoperative residual paralysis and respiratory status: A comparative study of Pancuronium and Vecuronium. Physiol Res 2000;49:455- 62.

11. Baillard C, Bourdiau S, Le Toumelin P, et al. Assessing residual neuromuscular blockade using acceleromyography can be deceptive in postoperative awake patients. Anesth Analg 2004;98: 854-7.

12. Nil Kaan, Ozlem Kocaturk, Ibrahim Kurt and Halil Cicek. The incidence of residual neuromuscular blockade associated with single dose of intermediate-acting neuromuscular blocking drug. Middle East J Anaesthesiol 2012; 21:535-541.

13. Naguib M, Kopman AF, Ensor JE. Neuromuscular monitoring and postoperative residual curarisation: A meta-analysis. Br J Anaesth 2007;98:302-16.

14. M. Nortona, D. Xaráa, D. Parentea, M. Barbosaa, F.J. Abelhaa. Residual neuromuscular block as a risk factor for critical respiratory events in the postanesthesia care unit. Rev Esp Anestesiol Reanem.2013;60:190-96.

15. TsaiCC, Chung HS, Chen PL, YuCM, Chen MS, HongCL. Postoperative residual curarization: Clinical observation in the post-anesthesia care unit. Chang Gung Med J. 2008; 31:364-8.

16. Eriksson LI, Sundman E, Olsson R, Nilsson L, Witt H, Ekberg O, et al. Functional assessment of the pharynx at rest and during swallowing in partially paralyzed humans: Simultaneous videomanometry and mechanomyography of awake human volunteers. Anesthesiology 1997;87:1035-43.

17. Kopman AF, Yee PS, Neuman GG. Relationship of the train of-four fade ratio to clinical signs and symptoms of residual paralysis in awake volunteers. Anesthesiology 1997;86:765-71.

18. C. Baillard, C. Clec'h, J. Catineau, F. Salhi, G. Gehan, M. Cupa et al. Postoperative residual neuromuscular block: A survey of management $\mathrm{Br}$ J Anaesth 2005;95: 622-6.

19. Butterly A, Bittner EA, George E, Sandberg WS, Eikermann M, Schmidt U. Postoperative residual curarization from intermediate-acting neuromuscular blocking agents delays recovery room discharge. Br. J Anaesth 2010; 105:304-9.

20. Tom Heier, James E. Caldwell. Impact of Hypothermia on the Response to Neuromuscular Blocking Drugs. Anesthesiology 2006; 104:1070-80. 


\begin{tabular}{|c|c|c|c|}
\hline & $\begin{array}{c}\text { Atracurium } \\
(\mathbf{n = 1 8 0})\end{array}$ & $\begin{array}{c}\text { Vecuronium } \\
(\mathbf{n = 1 8 0})\end{array}$ & $\begin{array}{c}\text { 'p' } \\
\text { value }\end{array}$ \\
\hline *Age & Patient characteristics & & \\
\hline \#Sex (F/M) & $35.96 \pm 12.22$ & $37.78 \pm 13.27$ & 0.176 \\
\hline *Height & $87 / 93$ & $78 / 102$ & 0.341 \\
\hline${ }^{*}$ Weight & $158.07 \pm 12.16$ & $158.94 \pm 11.14$ & 0.476 \\
\hline \multicolumn{2}{|c|}{$59.33 \pm 0.56$} & $59.67 \pm 10.13$ & 0.297 \\
\hline \#Type of surgery (GS/GY) & $125 / 55$ & $123 / 57$ & 0.820 \\
\hline $\begin{array}{c}\text { *Re-doses of the relaxants } \\
\text { *Core body temperature } \\
\text { at the end of surgery }\end{array}$ & $\begin{array}{c}2.44 \pm 1.38 \\
\text { Intra operative data }\end{array}$ & $1.53 \pm 1.23$ & 0.001 \\
\hline *Duration of Anaesthesia & $137.14 \pm 14$ & $135.58 \pm 56.27$ & 0.036 \\
\hline $\begin{array}{c}* \text { Time interval between } \\
\text { administration of reversal and } \\
\text { extubation }\end{array}$ & $6.97 \pm 1.60$ & 0.761 \\
\hline \multicolumn{2}{|c|}{ Table 1: Demographic and Intraoperative Variables of } \\
\hline \multicolumn{2}{|c|}{ Patients in the Two Groups. } \\
\hline
\end{tabular}

* Mean \pm SD ; \# number of patients; GS: General Surgery;GY: Gynaecology ( $<<0.05$ is Significant)

\begin{tabular}{|c|c|c|c|}
\hline \multirow{2}{*}{ TOF Ratios } & \multicolumn{2}{|c|}{ Group } & \multirow{2}{*}{ Total } \\
\cline { 2 - 4 } & Atracurium & Vecuronium & 196 \\
\hline \multirow{2}{*}{$<0.9$} & 84 & 112 & $54.4 \%$ \\
\cline { 2 - 4 } & $42.86 \%$ & $57.14 \%$ & 164 \\
\hline \multirow{2}{*}{0.9} & 96 & 68 & $45.6 \%$ \\
\cline { 2 - 4 } & $58.54 \%$ & $41.46 \%$ & Table 2: Comparison of TOF Ratios at the time of Tracheal Extubation between \\
the two groups: Incidence of Residual Neuromuscular Blockade
\end{tabular}

$P$ value $=0.003$

\begin{tabular}{|c|c|c|c|}
\hline \multirow{2}{*}{ TOF ratios } & \multicolumn{2}{|c|}{ Group } & \multirow{2}{*}{ Total } \\
\cline { 2 - 4 } & ATRACURIUM & VECURONIUM & 9 \\
\hline $0.7-0.79$ & 0 & 9 & 187 \\
\hline $0.8-0.89$ & $84(44.9 \%)$ & $103(55.1 \%)$ & 164 \\
\hline$\geq 0.9$ & $96(58.5 \%)$ & $68(41.5 \%)$ & 360 \\
\hline Total & 180 & 180 & \\
\hline \multicolumn{3}{|c|}{ Table 3: Comparison of the Severity of Residual Neuromuscular } \\
Blockade among the Two Groups
\end{tabular}

$\mathrm{P}=0.0001$ 